Editorial

\title{
Public Space in the New Urban Agenda: Research into Implementation
}

\author{
Michael W. Mehaffy ${ }^{1, *}$, Tigran Haas ${ }^{1}$ and Peter Elmlund ${ }^{2}$ \\ ${ }^{1}$ Centre for the Future of Places, KTH Royal Institute of Technology, 11428 Stockholm, Sweden; \\ E-Mails: michael.mehaffy@gmail.com (M.W.M.), tigran.haas@abe.kth.se (T.H.) \\ 2 Urban City Research, Ax:son Johnson Foundation, 10375 Stockholm, Sweden; E-Mail: peter.elmlund@axess.se \\ * Corresponding author
}

Submitted: 21 June 2019 | Published: 30 June 2019

\begin{abstract}
The New Urban Agenda is a landmark international framework for urbanisation for the next two decades, adopted by acclamation by all 193 countries of the United Nations. Nonetheless, implementation remains an enormous challenge, as does the related need for research evidence to inform practice. This thematic issue brings together research from a number of participants of the Future of Places conference series, contributing new research to inform the development and implementation of the New Urban Agenda, and with a focus on the fundamental topic of public space creation and improvement.
\end{abstract}

\section{Keywords}

evidence-based design; Future of Places; New Urban Agenda; public space; research into practice

\section{Issue}

This editorial is part of the issue "Public Space in the New Urban Agenda: Research into Implementation", edited by Michael W. Mehaffy (KTH Royal Institute of Technology, Sweden), Tigran Haas (KTH Royal Institute of Technology, Sweden), and Peter Elmlund (Axel and Margaret Ax:son Johnson Foundation, Sweden).

(C) 2019 by the authors; licensee Cogitatio (Lisbon, Portugal). This article is licensed under a Creative Commons Attribution 4.0 International License (CC BY).

\section{Introduction}

This thematic edition of Urban Planning brings together research by a number of the international scholars and practitioners who participated in the seminal Future of Places Conference series, contributing their evidencebased research toward development of UN-Habitat's New Urban Agenda. That document was later adopted by acclamation by all 193 member states of the United Nations in 2016, establishing a historic framework for urbanisation policy for the next two decades-a time of unprecedented rapid growth of cities and suburbs around the world, with unprecedented challenges as well as notable opportunities.

A key focus of the New Urban Agenda is on the critical role of public space in the formation and regeneration of healthy, prosperous and equitable cities. That was also a key focus of the earlier Future of Places partnership, launched in 2013 between UN-Habitat, Project for Public Spaces, and the Ax:son Johnson Foundation, its NGO host. Beginning that year, the conference series brought together over 1,500 researchers, practitioners, officials and activists, representing more than 700 organizations, 275 cities and 100 countries from every continent except Antarctica, forming a collaborative platform for research, implementation, networking and advocacy. One of the key themes of the series was to shift the thinking about city-building "from objects to places" (Elmlund, 2016).

Over the first three years leading up to the Habitat III conference, the forum included 77 peer-reviewed academic papers, 96 sessions, and 71 plenary speakers. The 2015 conference was also the first UN-Habitat Urban Thinkers Campus, and the forum also influenced the Sustainable Development Goals (notably 11.7), the Charter of Public Space, and other related documents.

Incorporating the contributions of its participants, the forum generated a series of key messages that contributed to the New Urban Agenda and the other documents, emphasizing the central role of public 
space frameworks as critical ingredients of healthy urbanisation:

The Future of Places affirms the role of public spaces as the connective network on which healthy cities and human settlements grow and prosper. Public spaces enable synergistic interaction and exchange, creativity and delight, and the transfer of knowledge and skills. Public spaces can help residents to improve their prosperity, health, happiness and wellbeing, and enrich their social relations and cultural life. (Future of Places, 2015)

Most of the papers presented in the conference series dealt in some way with the challenge of public spacewhat it is, why it matters, how it functions, how it fails, and how it can succeed, applying shareable evidencebased knowledge and tools. We noted that the issue of public space not only cuts across disciplines, but it is also situated at the intersection of a wide range of critical urban issues: economic inequality, racial and ethnic diversity, political conflict, cultural identity and expression, social capital, public involvement, and governance, among others.

Yet at just the historical moment when many are finally recognising its great value, public space is facing an unprecedented decline: increasingly privatised, diminished, or degraded by adjacent developments. Old models of "urban renewal" still have far too much sway over policy and practice-a point made emphatically by the authors of The Quito Papers, a companion publication to Habitat III whose authors also participated in the Future of Places.

There is thus an urgent need to share lessons about the formation, improvement and maintenance of public spaces around the world, including streets, parks, squares, pathways, and other components. We must moreover share specific tools and strategies toward implementation of the New Urban Agenda, based on evidence, and persuasive as well as useful to local implementers.

\section{Overview of the Articles}

The articles herein represent an important-and we think impressive-first step in that larger process. Reflecting field research from around the world, they report on the impacts of a range of public space strategies, conditions and challenges. The majority of the articles are versions of papers submitted for peer-review and accepted for presentation at the Future of Places conferences, out of a larger group of several hundred. Additional articles were submitted by authors who have participated in the Future of Places or its successor research hub, the Centre for the Future of Places based at KTH Royal Institute of Technology at Stockholm, Sweden. All of the articles herein have undergone entirely new peerreviews with final editorial decisions by ourselves as academic editors. We thank our authors for their patience with this additional review process, and for their valuable contributions to the literature. Following is a brief overview of the articles and topics.

Deore and Lathia (2019) address the critical topic of streets as public spaces and "engines of economic activities, social hubs, and platforms for civic engagement" (p. 138), in their article. Their field research examines "spatial analysis of 4,000 vendors at four different time points of the day, perception studies of their clientele disaggregated by gender, income and age, and their relationship with surrounding land-use and street hierarchy" (Deore \& Lathia, 2019, p. 138). They conclude with a series of actionable recommendations, aiming to maintain an equitable development model for street vending and economic opportunity.

Mahadevia and Lathia (2019) examine the central goal (in both the New Urban Agenda and the Sustainable Development Goals) of women's safety and inclusiveness in public spaces. In their article, they report on field research results from the riverfront in Ahmedabad, western India, and conclude with specific recommendations on proposed activities and space design, including increasing formal and informal surveillance, increasing everyday governance of basic amenities (lighting, toilets etc), promoting additional activities and services (sports, festivals, transit, etc.) and elevating the gender dimension in planning and design.

Brain (2019) examines public space as an "urban commons", and surveys literature on the links between "the social processes at stake in urban places, the spatial ordering of urban form and the construction of the forms of agency that enable us to make better places on purpose" (Brain, 2019, p. 162). He concludes that urbanism ultimately must be a political project, aimed at healing the disruptions of the urban commons.

In her article, Chidambara (2019) concludes that "walk is the predominant mode for LMC to/from transit stations" (p. 192), particularly for the first or last mile or kilometre, and reports that, within the Delhi research area, "all such stations with higher walk shares, within the same urban fabric, exhibit better performance with respect to placemaking"-defined as "the presence of street crossings, attractive landscaping, tree cover and signalisation" and "aesthetic or safety features, such as cleanliness, interesting sights and architecture" (p. 193).

Ghavampour and Vale (2019) examine the literature on current working models of placemaking and sustainability. They conclude that these concepts are still unacceptably vague, and that "there is need for a shift from the current model of placemaking towards a strong model of progress and balance in creating quality places" (Ghavampour \& Vale, 2019, p. 196). In particular, an over-emphasis on physical design under-emphasizes behaviour and meaning.

Papachristou and Rosas-Casals (2019) address measurement methodologies for Quality of Life (QoL), and report on an evolving "human scale development" paradigm to measure current levels of QoL. They pro- 
pose a methodology that can be applied to public space projects under the New Urban Agenda.

Gubic and Baloi (2019) report a hopeful and important case study from sub-Saharan Africa in their article. They observe "emerging forms of innovative collaboration and partnerships for public spaces involving all levels of the Rwandan government, development partners, the civil society sector, and other stakeholders" (Gubic \& Baloi, 2019, p. 223), but they note that additional innovative sources of funding are needed.

Ellery and Ellery (2019) survey existing research and conclude that a continuum of placemaking strategies is needed to improve the outcomes of public space projects. They propose a methodology based on Arnstein's ladder of citizen participation, aiming to increase the likelihood that a sense of place within the host community will be developed as an outcome of the planning and design process.

Finally, Del Aguila, Ghavampour and Vale (2019) describe a theory of place in public space, emerging in part from their survey of 160 users across four public spaces in Wellington, New Zealand. Drawing on previous research from E. C. Relph and others, they explore connections between physical settings and behaviour, finding that "anticipated behaviour in public space is defined by the affective and cognitive images of the physical setting" (Del Aguila et al., 2019, p. 250). They conclude that placemaking in design needs to shift emphasis, from articulating (fixed) preferences, to enabling interpretation and opportunity. In addition, they say, public spaces need marketing and promotion of activities to generate use and reuse, and to attract new users.

\section{Further Research Toward Implementation}

Work begun with the Future of Places forum continues, not only with the aforementioned Centre for the Future of Places, but with a range of other partnerships and projects. One project of note is a new database of research literature on public space, drawn from a range of disciplines including urban planning and design, geography, anthropology, environmental psychology, economics, and other fields. Unfortunately, the interchange of knowledge between these different disciplines on the subject of public space is minimal, and very few implementers are currently able to use this knowledge holistically. Therefore, the database will gather applicable empirical and field research into a working repository, and support the use of this resource to review, synthesize, draw new conclusions, and identify significant gaps in various areas of research. The mission will be to advance the creation of a new discipline called public space studies, which begins with the proposition that actionable knowledge about the ingredients of good public space exists and can be identified, shared and implemented.

In addition to our database project, we continue to partner with UN-Habitat and others on additional resources for implementation. One of these is the further development of new journal platforms such as the new Journal of Public Space, hosted by City Space Architecture in partnership with UN-Habitat. Another project is the development of peer-to-peer knowledge-sharing platforms, including a "wiki" for sharing of implementation tools and strategies. In addition, we are engaged with the development of a number of books, white papers and other publications as resources for implementation.

All of these resources are focused upon "research into practice" and back again: that is, applying an evidence-based approach, learning from actual outcomes, applying that to new practice, and drawing lessons back into research again. In this way, our knowledge and our effectiveness in implementing the New Urban Agenda can grow and mature. We can apply that knowledge to greatly accelerate progress on the challenges of the next several decades, including social and economic development for all, conservation of resources and critical ecologies, mitigation of and adaptation to the impacts of climate change, and improvement of the health and livability of cities around the world.

The Future of Places therefore continues to evolve as a platform, with a focus on public space and placeand with it our belief that public space offers a powerful framework to achieve a new generation of healthy and sustainable cities.

\section{Acknowledgments}

The guest editors are grateful for institutional support from the Ax:son Johnson Foundation, KTH Royal Institute of Technology, Urban Planning and Cogitatio Press.

\section{Conflict of Interests}

The authors declare no conflict of interests.

\section{References}

Brain, D. (2019). Reconstituting the urban commons: Public space, social capital and the project of urbanism. Urban Planning, 4(2), 169-182.

Chidambara. (2019). Walking the first/last mile to/from transit: Placemaking a key determinant. Urban Planning, 4(2), 183-195.

Del Aguila, M., Ghavampour, E., \& Vale, B. (2019). Theory of place in public space. Urban Planning, 4(2), 249-259.

Deore, P., \& Lathia, S. (2019). Streets as public spaces: Lessons from street vending in Ahmedabad, India. Urban Planning, 4(2), 138-153.

Ellery, J. P., \& Ellery, J. (2019). Strengthening community sense of place through placemaking. Urban Planning, 4(2), 238-248.

Elmlund, P. (2016). A thriving future of places; Placemaking as the New Urban Agenda. Urban Gateway. Retrieved from http://www.urbangateway.org/ document/thriving-future-places-place-making- 
new-urban-agenda

Future of Places. (2015). Key messages from the Future of Places. Retrieved from https://unhabitat.org/wpcontent/uploads/2015/10/Key-Messages-from-theFuture-of-Places.pdf

Ghavampour, E., \& Vale, B. (2019). Revisiting the "model of place": A comparative study of placemaking and sustainability. Urban Planning, 4(2), 196-206.

Gubic, I., \& Baloi, O. (2019). Implementing the new ur- ban agenda in Rwanda: Nation-wide public space initiatives. Urban Planning, 4(2), 223-236.

Mahadevia, D., \& Lathia, S. (2019). Women's safety and public spaces: Lessons from the Sabarmati riverfront, India. Urban Planning, 4(2), 154-168.

Papachristou, I. A., \& Rosas-Casals, M. (2019). Maximising the degree of user choice: A simple tool to measure current levels of quality of life in urban environments. Urban Planning, 4(2), 207-222.

\section{About the Authors}

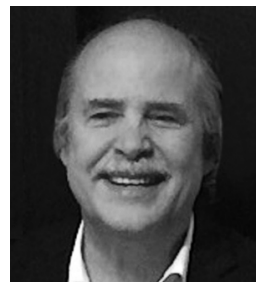

Michael W. Mehaffy, PhD, is Senior Researcher with the Ax:son Johnson Foundation and the Centre for the Future of Places at KTH Royal Institute of Technology in Stockholm, and Executive Director of the Sustasis Foundation, an urban sustainability think-tank based in Portland, Oregon. He has held teaching and/or research appointments at seven graduate institutions in six countries, and he is on the editorial boards of two international journals of urban design. He received his PhD in Architecture at the Delft University of Technology in the Netherlands.

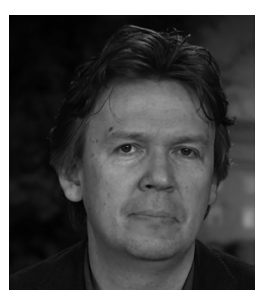

Tigran Haas, PhD, is Associate Professor and Director of the Centre for the Future of Places at KTH Royal Institute of Technology in Stockholm. He holds advanced degrees in Architecture, Urban Planning and Urban Design, Environmental Science and Regional Planning. He was a guest professor at the Zagreb School of Economics and Management (ZSEM) and was Director and Chair of Civitas Athenaeum Laboratory (CAL) as well as co-founder of the first ever Scandinavian master's in Urban Planning and Design.

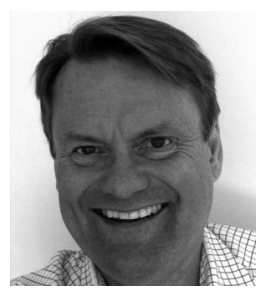

Peter Elmlund is Director of the Urban City Research programme at Ax:son Jonson Foundation, a Swedish institution active in urban research on policy and practice. Under Peter's leadership, Urban City Research has organized numerous major international conferences and seminars on contemporary urban planning and design. The programme also funds research and education at many universities in Europe and the USA, a key at the Royal Institute of Technology, Stockholm, where Peter is a guest researcher in residence. 